\title{
Characterization of High Molecular Weight Mucins of Rabbit Bladder
}

\author{
Arivalagan Muthusamy*, D. Channe Gowda and Veer P. Bhavanandan
}

Department of Biochemistry and Molecular Biology, The Pennsylvania State University College of Medicine, Hershey, PA 17033, USA

\begin{abstract}
Epithelial mucin glycoproteins of bladder act as an effective barrier against invasion by pathogenic microorganisms and injury by toxic substances in urine. Although these glycoconjugates play important roles in the pathophysiology of bladder disorders such as intestinal cystisis, cancer, and urinary tract infections, they have not been characterized in detail either in humans or in animals. Rabbits could be useful for developing models for studying bladder disorders. In this study, we purified and partially characterized two major high molecular weight rabbit bladder mucin glycoproteins, designated $\mathrm{RBM}_{1}$ and $\mathrm{RBM}_{2}$, found in urine. Consistent with their mucin characteristics, amino acid compositions showed have high levels of serine, glutamic acid, proline, glycine and alanine, which together comprise $34 \%$ and $42 \%$ of the total amino acids in $\mathrm{RBM}_{1}$ and $\mathrm{RBM}_{2}$, respectively. Carbohydrate compositional analysis indicated that $\mathrm{RBM}_{1}$ and $\mathrm{RBM}_{2}$ consist of $N$-acetylgalactosamine (GalNAc), $N$-acetylglucosamine (GlcNAc), galactose (Gal), $N$-acetylneuraminic acid (NeuAc) and fucose (Fuc) in the molar ratio of 1.0: 0.82: 0.12: 0.30: 0.02 and 1.0: 1.03: 0.46: 0.16: 0.05, respectively; mannose (Man) was not detected in either mucin. Both mucin fractions were strongly reactive to wheat germ agglutinin, but not to $\mathrm{Ca} 2$ antibody specific to a human tumor mucin antigen (asialylated carbohydrate linked to protein core), suggesting that most of the galactosyl residues of oligosaccharides are sialylated. Together, the data suggest that rabbit mucin glycoproteins characterized here are distinctively different from MUC1 mucin glycoprotein found in human urine.
\end{abstract}

Key Words: Rabbit bladder, Urothelium, Urine, Epithelial mucin glycoproteins, Biochemical characterization.

\section{INTRODUCTION}

Epithelial surfaces of the animals such as the tracheobronchial, gastrointestinal, and urogenital tracts that are in direct contact with the external environment are protected by a layer of mucus secretions $[1,2]$. The bladder is lined by transitional epithelium (urothelium), which is a highly specialized tissue that has to accommodate changes in its luminal surface area when the bladder fills and contracts. More importantly, the transitional epithelium acts as a permeability barrier and provides protection from the hostile environment consisting of chemicals and microbes. There is considerable evidence that implicate the association of mucin glycoconjugates in the pathophysiology of bladder disorders such as urinary tract infections [3-5], interstitial cystitis $[6,7]$ and bladder carcinoma $[8,9]$. The abundance of glycoproteins on the luminal surface of bladder is demonstrated by the very intense staining of rabbit and human bladders by antiglycoprotein antibodies and lectins [10-12]. Previously, we have identified MUC1 glycoprotein (referred to as epitectin) as the major mucin glycoprotein of human [13] and rabbit urothelium [14]. These and other studies in our laboratory [15] demonstrate that mucin glycoproteins are the predominant glycoconjugates in mammalian bladder rather than glycosaminoglycans as suggested by Parsons and co-workers $[16,17]$. However, in contrast to mucins on the tracheal, intestinal and cervical epithelium of animals, those associated with the bladder epithelium have not been well charac-

*Address correspondence to this author at the Department of Orthopedics and Rehabilitation, Division of Musculoskeletal Sciences, The Pennsylvania State University College of Medicine, 500 University Dr., Hershey, PA 17033, USA; Tel: 1-717 531 8980; Fax: 1-717 531 7583;

E-mail: arivu@psu.edu terized. This could be due to the difficulty in obtaining adequate quantities of fresh bladder tissue.

The glycoconjugates of the bladder epithelium are continually shed to the urine. This enabled us to purify and structurally characterize a human bladder-associated mucin MUC1 from pooled human urine [18]. Sedimentation equilibrium analysis and gel filtration revealed that human urine MUC1 (epitectin) is a polydisperse preparation with molecular weights ranging from about 0.9 to $1.3 \times 10^{6}$. Epitectin was found to contain $50 \%$ carbohydrate by weight that is present as both sialylated and non-sialyated $O$-linked oligosaccharides having core 1 and 2 structures, Gal $\rightarrow 3$ GalNAc, GlcNAc1 $\rightarrow 6(\mathrm{Gal} 1 \rightarrow 3) \mathrm{GalNAc}$ and $\mathrm{Gal} \rightarrow 4 \mathrm{GlcNAc} 1 \rightarrow$ $6(\mathrm{Gall} \rightarrow 3)$ GalNAc. One proposed function for MUC1 is the protection of the epithelium from extreme $\mathrm{pH}$ and osmolarity $[13,19]$. Another bladder glycoprotein, GP51, resembling that reported to be decreased in the urine of interstitial cystitis patients compared to urine of healthy individuals, has been purified from rabbit bladder [20]. Previously, our laboratory has purified a major mucin glycoprotein with a molecular mass of about $245 \mathrm{kDa}$ from radio labeled rabbit bladder explants and identified it as the rabbit homolog of human MUC1 [14]. Here, we report the purification of milligram quantities of two high molecular weight mucins from rabbit urine and biochemical characteristics of those mucins.

\section{MATERIALS AND METHODS}

\section{Materials}

Healthy female rabbits were maintained at the Animal facility of the Milton Hershey Medical Center. Sepharose CL-4B and cesium trifluoroacetate (CsTFA) were purchased from Pharmacia (Piscataway, NJ). Carbo Pac PA1 column 
and sugar reference standards were from Dionex (Sunnyvale, CA). Amino acid standards were from Pierce Biotechnology (Rockford, IL). Biotinylated wheat germ agglutinin and HRP conjugated streptavidin were from Vector Laboratories (Burlingham, CA). Enhanced chemiluminescent reagent was from GE Health Care (Pittsburg, PA). Ca2 monoclonal antibody specific to human mucin glycoprotein antigen was a gift from Professor Henry Harris, University of Oxford. All other chemicals were of analytical grade.

\section{Collection and Processing of Rabbit Urine}

Urine samples collected from the healthy rabbits were centrifuged to remove cell debris, and stored in $-20^{\circ} \mathrm{C}$ until used. After accumulating about 4 liters, the urine was thawed, concentrated by ultrafiltration at $4^{\circ} \mathrm{C}$ using Amicon YM-30 membrane with a molecular weight cutoff of 30,000. The concentrated samples were then dialyzed against distilled water at $4{ }^{\circ} \mathrm{C}$, freeze dried, and stored at $-20^{\circ} \mathrm{C}$ until used.

\section{Perchloric Acid Precipitation}

The freeze-dried rabbit urine was dissolved in double distilled water at $4{ }^{\circ} \mathrm{C}$. While maintaining the solution at $4{ }^{\circ} \mathrm{C}$ (ice bath), an equal volume of $1.3 \mathrm{~N}$ perchloric acid was added with stirring [21]. The cloudy solution was incubated for $30 \mathrm{~min}$ with occasional mixing and then centrifuged at $7,000 \mathrm{rpm}$ for $15 \mathrm{~min}$ at $4{ }^{\circ} \mathrm{C}$ to remove the precipitated protein. The precipitate was discarded and the supernatant, kept in an ice bath, was neutralized by addition of ice-cold $1.2 \mathrm{M}$ potassium hydroxide solution. The precipitated potassium perchlorate was removed by centrifugation at 7,000 rpm for $15 \mathrm{~min}$ at $4^{\circ} \mathrm{C}$. The supernatant was dialyzed against double distilled water at $4^{\circ} \mathrm{C}$ for $48 \mathrm{~h}$ and lyophilized to recover the glycoconjugates (mucins and glycosaminoglycans) containing high carbohydrate content.

\section{Gel Filtration Chromatography}

The perchloric acid-soluble material was reconstituted and fractionated on a Sepharose CL-4B column $(7 \times 83 \mathrm{~cm})$ pre-equilibrated with phosphate buffered saline (PBS). Fractions (16.5 ml each) were collected and aliquots analyzed for protein and sialic acid. The sialic acid containing fractions were pooled, dialyzed, and lyophilized.

\section{CsTFA Density Gradient Centrifugation}

The material obtained from gel filtration chromatography was re-dissolved in $50 \mathrm{mM}$ Tris- $\mathrm{HCl}$ buffer, $\mathrm{pH} 8.0$ containing $4 \mathrm{M}$ guanidine- $\mathrm{HCl}$ by stirring overnight at $4^{\circ} \mathrm{C}$ [22]. The solution was centrifuged at $3000 \mathrm{rpm}$ in a Sorvall centrifuge for 5 min to remove a small amount of insoluble material. The density of the supernatant was adjusted to $1.35 \mathrm{~g} / \mathrm{ml}$ with CsTFA, and the solution centrifuged at $14^{\circ} \mathrm{C}$ in a Beckman 70 Ti rotor for $72 \mathrm{~h}$ at 42,000 rpm. Fractions (1 ml) were collected by gentle aspiration from the bottom of tube and densities of every fifth fraction determined by weighing $100 \mu \mathrm{l}$ in a calibrated micropipette. Aliquots of each fraction were analyzed for sialic acid. The fractions positive for sialic acids were pooled and the material recovered by exhaustive dialysis and lyophilization.

\section{Cellulose Acetate Electrophoresis}

Cellulose acetate electrophoresis was performed in a Beckman R-101 microzone electrophoresis cell with pyri- dine-formic acid buffer, pH 5.0 at $4 \mathrm{~mA}$ for $20 \mathrm{~min}$ [23]. The mucins and glycoprotein standards on the cellulose acetate strips were detected by staining with $0.1 \%$ Alcian blue in $0.5 \%$ aqueous acetic acid [24] or the periodate acid-Schiff reagent [25].

\section{Gel Electrophoresis}

SDS-polyacrylamide electrophoresis was performed by using $4-15 \%$ mini gradient gels (Bio-Rad) and 2\% polyacrylamide gels containing $0.5 \%$ agarose [26]. After electrophoresis, the gels were stained with Coomassie brilliant blue followed by silver reagent [27] for detection of proteins or with the periodate acid-Schiff reagent for detection of glycosylated proteins.

\section{Lectin Blot and Western Blot Analyses}

After SDS-PAGE, the proteins from the gels were transferred to nitrocellulose membrane using Tris-glycine buffer containing $0.037 \%$ SDS and $20 \%$ methanol at $80 \mathrm{~mA}$ overnight at $4{ }^{\circ} \mathrm{C}$. The membrane was incubated with biotinlylated wheat germ agglutinin $(50 \mu \mathrm{g} / \mathrm{ml})$ for $1 \mathrm{~h}$ at room temperature, washed and probed with HRP-conjugated streptavidin $(50 \mathrm{ng} / \mathrm{ml})$ for $1 \mathrm{~h}$ at room temperature. The bound streptavidin-HRP was detected using the enhanced chemiluminescence system.

For Western blot analysis, membranes containing rabbit bladder mucin fractions were probed with $\mathrm{Ca} 2$ antibody [28] followed by HRP-conjugated anti-mouse IgG secondary antibody. The bound antibody was detected using the enhanced chemiluminescence system as above.

\section{Colorimetric Analysis for Proteins and Carbohydrates}

Chromatographic column effluents and CsTFA density gradient fractions were screened for protein by absorbance at $280 \mathrm{~nm}$. Sialic acid in the fractions was measured by thiobarbituric acid assay after hydrolysis with $0.1 \mathrm{~N} \mathrm{H}_{2} \mathrm{SO}_{4}$ for $1 \mathrm{~h}$ at $80^{\circ} \mathrm{C}$ [29].

\section{Amino Acid Analysis}

Amino acid composition was determined by Pico-Tag analysis using reverse phase HPLC [26]. The mucin samples $(200 \mu \mathrm{g})$ were acid hydrolyzed with $6 \mathrm{~N} \mathrm{HCl}$ (Pierce Biotechnology, Rockford, IL) in vacuo at $110^{\circ} \mathrm{C}$ for $18 \mathrm{~h}$ and the hydrolysate dried. The material was dissolved in a solution consisting of ethanol, water, and triethylamine in the ratios of 2:2:1 (v/v/v) and redried. These samples were dissolved in derivatizing solution consisting of ethanol, water, triethylamine, and phenylisothiocyanate in the ratios of $7: 1: 1: 1$ $(\mathrm{v} / \mathrm{v} / \mathrm{v} / \mathrm{v})$. The mixture was incubated at room temperature for $5 \mathrm{~min}$ and dried under vacuum in a Speed-Vac. The derivatized samples were analyzed by HPLC on a 3.9 x 300mm C18 Pico-Tag column (Waters, Millipore) using aqueous sodium acetate and acetonitrile gradient as described [30] and detected at $245 \mathrm{~nm}$. The amino acid peaks were quantitated by correcting for response factors of standard amino acids derivatized and analyzed as above.

\section{Carbohydrate Compositional Analysis}

Hexose and hexosamine content of the samples were analyzed by high-performance anion-exchange chromatography using a Dionex HPLC equipped with a pulse amperometric detector [31]. For neutral sugars and amino sug- 


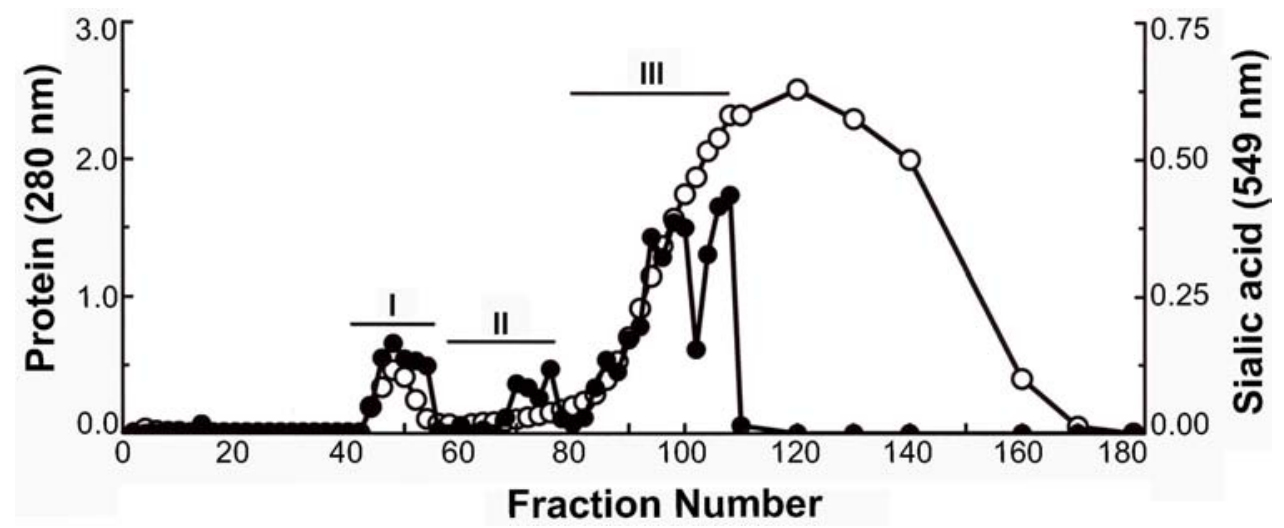

Fig. (1). Gel filtration chromatography of glycoproteins isolated from rabbit urine by perchloric acid precipitation on Sepharose CL-4B columns $(7 \times 83 \mathrm{~cm})$. The column was eluted with PBS and fractions $(16.5 \mathrm{ml})$ collected and aliquots analyzed for protein at $280 \mathrm{~nm}(\mathrm{o})$ and $N$ acetylneuraminic acid at $549 \mathrm{~nm}(\bullet)$ by thiobarbituric acid assay. Fractions in Peaks I, II and III were pooled as indicated by horizontal bars.

ars, the samples were hydrolyzed in $2 \mathrm{M}$ trifluoroacetic acid at $100^{\circ} \mathrm{C}$ for $8 \mathrm{~h}$. The dried hydrolysates were dissolved in HPLC grade water and analyzed on a Carbo Pac PA-1 column by isocratic elution with $14 \mathrm{mM}$ sodium hydroxide. Sialic acids (NeuNAc and NeuNGly) were determined after hydrolysis with $0.1 \mathrm{~N} \mathrm{H}_{2} \mathrm{SO}_{4}$ at $80^{\circ} \mathrm{C}$ for $1 \mathrm{~h}$. The hydrolysates were neutralized with $\mathrm{NaOH}$ and an aliquot analyzed on the above column. Elution was with $10 \mathrm{mM} \mathrm{NaOAc/102}$ $\mathrm{mM} \mathrm{NaOH}$ for $10 \mathrm{~min}$ followed by a gradient of $10 \mathrm{mM}$ $\mathrm{NaOAc} / 102 \mathrm{mM} \mathrm{NaOH}$ to $40 \mathrm{mM} \mathrm{NaOAc} / 60 \mathrm{mM} \mathrm{NaOH}$ over the next $20 \mathrm{~min}$ and finally $200 \mathrm{mM} \mathrm{NaOAc} / 60 \mathrm{mM}$ $\mathrm{NaOH}$ for $10 \mathrm{~min}$. These analyses were performed at ambient temperature at a flow rate of $1 \mathrm{ml} / \mathrm{min}$.

\section{RESULTS AND DISCUSSION}

Rabbit bladder mucin was purified from pooled urine because urine from an individual rabbit was insufficient for biochemical characterization. Pooled urine samples were subjected to ultrafiltration using YM-30 membrane to desalt and remove low molecular weight material and the concentrate freeze-dried. In a typical experiment, about 4 liters of urine yielded $633 \mathrm{mg}$ of dry powder. This material was then treated with perchloric acid to precipitate proteins and glycoproteins of low carbohydrate content. Mucins that have high carbohydrate content are soluble in perchloric acid and therefore, remain in the supernatant. After perchloric acid precipitation, the supernatant gave $30 \mathrm{mg}$ of glycoconjugates. Sepharose CL-4B column chromatography of the perchloric acid-soluble material yielded three fractions; the high molecular size CL-4B excluded fraction (I), the intermediate size material just included in CL-4B (II) and protein-rich low molecular weight material (III) (Fig. 1).

Material corresponding to Peak I in Fig. (1) that contained high molecular weight mucins was subjected to density gradient centrifugation under dissociative conditions using CsTFA [22]. This procedure resolved Peak I material into two distinct fractions; a typical sedimentation profile for the CsTFA density gradient centrifugation of Peak I material is illustrated in Fig. (2). Thus, a high-density $(\sim 1.47)$ fraction (designated $\mathrm{RBM}_{1}$ ) and a well-resolved lower density $(\sim 1.42)$ fraction $\left(\mathrm{RBM}_{2}\right)$ were obtained (Fig. 2). The purified $\mathrm{RBM}_{1}$ and $\mathrm{RBM}_{2}$ fractions were used for biochemical characterization.

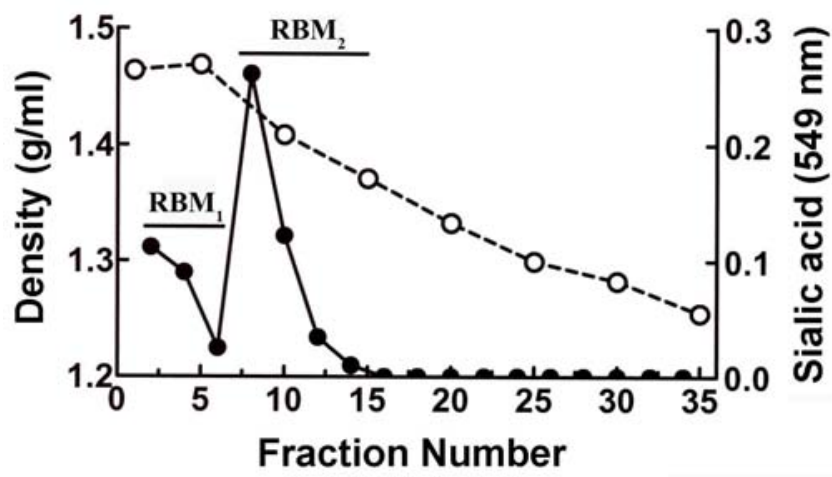

Fig. (2). CsTFA density gradient centrifugation of the high molecular weight mucins from rabbit urine. The material eluting in the void volume (Peak I) of Sepharose CL-4B column was subjected to CsTFA density gradient centrifugation. The gradients were fractionated and fractions analyzed for density (०) and $N$-acetylneuraminic acid $(\bullet)$. The mucin glycoproteins in the Peaks $\mathrm{RBM}_{1}$ and $\mathrm{RBM}_{2}$ were pooled as indicated by the horizontal bars, dialyzed, and lyophilized.

The purity of the high-molecular weight rabbit bladder mucin fractions $\left(\mathrm{RBM}_{1}\right.$ and $\left.\mathrm{RBM}_{2}\right)$ were analyzed by gel electrophoresis in the presence of SDS using $4-15 \%$ gradient polyacrylamide mini gels, and $2 \%$ polyacrylamide and $0.5 \%$ agarose composite vertical slab gels. The polyacrylamide gels did not reveal any Coomassie blue or PAS stained low molecular weight material confirming that the preparations were free of low molecular protein/glycoprotein contaminants. As expected for high molecular weight and highly glycosylated mucins, both $\mathrm{RBM}_{1}$ and $\mathrm{RBM}_{2}$ neither entered the gel nor stained appreciably with Coomassie blue (not shown). On polyacrylamide-agarose composite gels, $\mathrm{RBM}_{1}$ and $\mathrm{RBM}_{2}$, each gave a single broad band that stained strongly with the PAS reagent and had mobility similar to ovine submaxillary mucin of molecular weight of about 2 million; no other bands were detectable on these gels by any of the staining reagents used (Fig. 3, lanes 1 and 2). Because of the lack of high-molecular-weight glycoprotein standards and the abnormal behavior of highly glycosylated proteins in SDS-PAGE, it was not possible to estimate the molecular weight of rabbit bladder mucin fractions based on their electrophoretic mobility. However, the bladder mucins eluted in 
the void area of Sepharose CL-4B and had mobility similar to that of ovine submaxillary mucin in polyacrylamideagarose gels. Therefore, it can be estimated that $\mathrm{RBM}_{1}$ and $\mathrm{RBM}_{2}$ have 'apparent' molecular masses of $2.0 \times 10^{6}$ daltons or greater. On cellulose acetate electrophoresis, the mucin fractions, $\mathrm{RBM}_{1}$ and $\mathrm{RBM}_{2}$, each gave a single band of mobility intermediate between that of the porcine gastric mucin and hyaluronic acid; no glycosaminoglycan contaminants were detected in the mucin fractions (not shown). On the lectin blot analysis, the rabbit bladder mucin fraction $\mathrm{RBM}_{1}$ showed high reactivity with wheat germ agglutinin (Fig. 3, lane 7) suggesting the presence of a high density of terminal NeuAc and/or GlcNAc residues [32, 33]. Rabbit bladder mucin fraction $\mathrm{RBM}_{2}$ also strongly reacted with wheat germ agglutinin (not shown). Western blot analysis of the rabbit bladder mucin fractions using $\mathrm{Ca} 2$ antibody did not show any cross reactivity. These results taken together with carbohydrate composition indicate that the oligosaccharide moieties of $\mathrm{RBM}_{1}$ and $\mathrm{RBM}_{2}$ are different from those in the high molecular weight MUC1 (epitectin) purified from human urine and the MUCI homolog of rabbit bladder explant $[13,18]$.

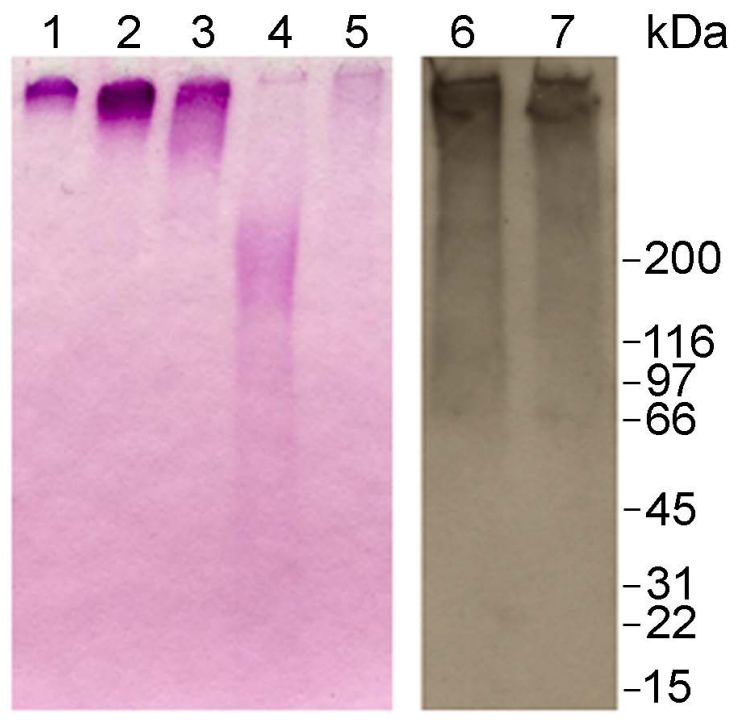

Fig. 3.

Fig. (3). SDS-polyacrylamide gel electrophoresis and Western blot analysis of rabbit bladder mucins. The purified mucin fractions $\mathrm{RBM}_{1}$ and $\mathrm{RBM}_{2}$ (see Fig. 2) and lower molecular weight glycoproteins fractions (Peak II and III in Fig. 1) were analyzed on 4-15\% gradient polyacarylamide gels and the gels stained with the PAS reagent. Lanes 1 and 2, $\mathrm{RBM}_{1}$ and $\mathrm{RBM}_{2}$. Lanes 3 and 4, glycoprotein fractions eluted in Peaks II and III (Fig. 1), respectively. Lane 5, ovine submaxillary gland mucin. Lanes 6 and 7, ovine submaxillary gland mucin and $\mathrm{RBM}_{1}$, respectively were electrophoresed as above, transferred to nitrocellulose membranes, treated with biotinylated wheat germ agglutinin followed by streptavidinHRP conjugate, and detected with the chemiluminescent reagent. Similar result was observed with rabbit bladder mucin fraction $\mathrm{RBM}_{2}$ (not shown).

Amino acid composition of rabbit bladder mucin fractions $\mathrm{RBM}_{1}$ and $\mathrm{RBM}_{2}$ is shown in Table $\mathbf{1} . \mathrm{RBM}_{1}$ and $\mathrm{RBM}_{2}$ have composition characteristics of mucins, that is, a high content of serine, glutamic acid, proline, and glycine, which together comprise about $34 \%$ and $42 \%$ of the total, respectively. The monosaccharide compositions of $\mathrm{RBM}_{1}$ and $\mathrm{RBM}_{2}$ are shown in Table 2 . The molar ratios of GalNAc, GlcNAc, Gal, NeuAc, and Fuc in fractions $\mathrm{RBM}_{1}$ and $\mathrm{RBM}_{2}$ were 1.0: 0.82: 0.12: 0.30: 0.02 and 1.0: 1.03: 0.46: $0.16: 0.05$, respectively. These values are typical of mucins in that they had high content of GalNAc and no detectable quantity of Man. Analysis for uronic acids by carbazole assay [34] was negative. These results confirm that the mucin fractions $\mathrm{RBM}_{1}$ and $\mathrm{RBM}_{2}$ were free of nucleic acid and glycosaminoglycans contaminants.

Table 1. Amino Acid Analysis of Rabbit Bladder Mucins

\begin{tabular}{|c|c|c|}
\hline & \multicolumn{2}{|c|}{ Amino Acid Residues $/ 1000$ Residues } \\
\hline & $\mathbf{R B M}_{1}$ & $\mathbf{R B M}_{2}$ \\
\hline Aspartic acid & ND & ND \\
\hline Glutamic acid & 16 & 92 \\
\hline Serine & 39 & 65 \\
\hline Glycine & 213 & 115 \\
\hline Histidine & 172 & 277 \\
\hline Arginine & ND & 45 \\
\hline Threonine & ND & ND \\
\hline Alanine & ND & 42 \\
\hline Proline & 72 & 147 \\
\hline Tyrosine & 32 & ND \\
\hline Valine & ND & ND \\
\hline Methionine & 32 & ND \\
\hline Cystine & 177 & ND \\
\hline Isoleucine & 144 & 181 \\
\hline Leucine & 20 & 36 \\
\hline Phenylalanine & 82 & ND \\
\hline Lysine & ND & ND \\
\hline
\end{tabular}

${ }^{\text {a } E s t i m a t e d ~ b y ~ P i c o-T a g ~ a n a l y s i s ~ u s i n g ~ r e v e r s e ~ p h a s e ~ H P L C . ~}$ ND: Not detected.

The glycoproteins in the urine have been analyzed extensively in order to evaluate the disease process affecting the urinary bladder, kidneys and urogenital tract [35]. Several low molecular weight glycoproteins such as Tamm-Horsfall glycoprotein (THGP)/Uromodulin, GP51, Fetuin-A, beta 2glycoprotein-1, C-reactive protein, Amyloid beta A4 protein, Alpha-1-inhibitor 3, Vitamin D-binding protein, Kallikrein 3 , uronic-acid rich protein (UAP) are found abundantly in mammalian urine [14, 20, 35-39]. However, the results of our studies reveal that the high molecular weight $\mathrm{RBM}_{1}$ and $\mathrm{RBM}_{2}$ mucin fractions we have characterized are distinct from these glycoproteins including THGP as well as the MUC1 mucins of human and rabbit bladder that we have previously reported $[13,18]$. 
Table 2. Carbohydrate Compositions of Rabbit Bladder Mucins

\begin{tabular}{|c|c|c|c|c|}
\hline \multirow{2}{*}{$\begin{array}{c}\text { Monosaccharides } \\
\end{array}$} & \multicolumn{2}{|c|}{ Monosaccharide Composition } \\
\cline { 2 - 5 } & \% weight & molar ratio & \multicolumn{3}{c|}{ RBM $^{2}$} \\
\cline { 2 - 5 } & 1 & 0.02 & 2 & 17 \\
\hline \hline Fucose & 6 & 0.12 & 37 & 0.05 \\
\hline Galactose & 44 & 1.00 & 38 & 1.00 \\
\hline Galactosamine & 36 & 0.82 & 6 & 1.03 \\
\hline Glucosamine & 13 & 0.30 & & 0.16 \\
\hline
\end{tabular}

${ }^{\mathrm{a}}$ Analyzed by the high-pH anion-exchange HPLC.

The nature of glycoconjugates eluting in Peaks II and III of Sepharose CL-4B column (Fig. 1) were also examined. SDS-PAGE (not shown) and agarose gel electrophoresis (Fig. 3, lanes 3 and 4) showed the presence of several low molecular weight proteins and glycoproteins. Monosaccharide analysis indicated that Peak II and Peak III materials contain significant amount of $\mathrm{N}$-linked glycoproteins as revealed by the presence of substantial amount of mannose. Since our focus in these studies was mucins, further purification and characterization of peaks II and III material was not undertaken.

In summary, we have purified and characterized two high molecular weight mucins designated as $\mathrm{RBM}_{1}$ and $\mathrm{RBM}_{2}$ from rabbit urine. The results show that it is possible to purify milligram quantities of bladder epithelial mucin glycoproteins from rabbit urine for detailed biochemical characterization. Based on analogy to previous work on MUC1 glycoprotein purified from human urine [18] and evidence that high molecular weight mucin synthesized by rabbit bladder in explants cultures were shed into the media [12], it can be inferred that these mucins originate from the bladder epithelium. The oligosaccharide of rabbit mucins appears to be relatively small in size terminating with either sialic acid or GlcNAc. Further detailed biochemical studies should aid in understanding the roles of epithelial mucins in the pathophysiology of bladder.

\section{ACKNOWLEDGEMENTS}

We wish to acknowledge Mostafa Sheykhnazari for technical assistance and Dr. D. R. Erickson for her interest and support of these studies. These studies were supported in part by USPHS grant DK57266.

\section{REFERENCES}

[1] Corfield T. Mucus glycoproteins, super glycoforms: how to solve a sticky problem? Glycoconj J 1992; 9: 217-21.

[2] Verma M, Davidson EA. Mucin genes: structure, expression and regulation. Glycoconj J 1994; 11: 172-9.

[3] Chiarini F, Mastromarino P, Mansi A, Rieti S, Orsi N. Role of membrane glycosphingolipids as Pseudomonas aeruginosa adhesin receptor in rabbit bladder mucosa. Microbiologica 1990; 13: 91-5.

[4] Lanne B, Olsson BM, Jovall PA, et al. Glycoconjugate receptors for P-fimbriated Escherichia coli in the mouse. An animal model of urinary tract infection. J Biol Chem 1995; 270: 9017-25.

[5] Zopf D, Roth S. Oligosaccharide anti-infective agents. Lancet 1996; 347: 1017-21.

[6] Moskowitz MO, Byrne DS, Callahan HJ, Parsons CL, Valderrama E, Moldwin RM. Decreased expression of a glycoprotein compo- nent of bladder surface mucin (GP1) in interstitial cystitis. J Urol 1994; 151; 343-5.

[7] Hurst RE, Roy JB, Min KW, et al. A deficit of chondroitin sulfate proteoglycans on the bladder uroepithelium in interstitial cystitis. Urology 1996; 48; 817-21.

[8] Walsh MD, Hohn BG, Thong W, et al. Mucin expression by transitional cell carcinomas of the bladder. Br J Urol 1994; 73: 256-62.

[9] Bergeron A, LaRue H, Fradet Y. Biochemical analysis of a bladder-cancer-associated mucin: structural features and epitope characterization. Biochem J 1997; 321: 889-95.

[10] Walker SR, Callahan HJ, Fritz R, Mulholland SG. Distribution of rabbit mucosal glycoprotein throughout urinary tract. Urology 1989; 33: 127-30.

[11] Grist M, Chakraborty J. Identification of a mucin layer in the urinary bladder. Urology 1994; 44: 26-33.

[12] Buckley M, Xin P, Washington S, Herb N, Erickson D, Bhavanandan VP. Lectin histochemical examination of rabbit bladder glycoproteins and characterization of a mucin isolated from the bladder mucosa. Arch Biochem Biophys 2000; 375: 270-7.

[13] Higuchi T, Xin P, Buckley MS, Erickson DR, Bhavanandan VP. Characterization of the rabbit homolog of human MUC1 glycoprotein isolated from bladder by affinity chromatography on immobilized jacalin. Glycobiology 2000; 10: 659-67.

[14] Buckley MS, Washington S, Laurent C, Erickson DR, Bhavananadan VP. Characterization and immunohistochemical localization of the glycoconjugates of the rabbit bladder mucosa. Arch Biochem Biophys 1996; 330: 163-73.

[15] Bhavanandan VP. Glycosaminoglycans and glycoproteins of animal bladder. Connective Tissue 2001; 33: 245-52.

[16] Parsons CL, Stauffer C, Schmidt JD. Bladder-surface glycosaminoglycans: an efficient mechanism of environmental adaptation. Science 1980; 208: 605-7.

[17] Parsons CL, Boychuk D, Jones S, Hurst R, Callahan H. Bladder surface glycosaminoglycans: an epithelial permeability barrier. J Urol 1990; 143: 139-42.

[18] Bhavanandan VP, Zhu Q, Yamakami K, et al. Purification and characterization of the MUC1 mucin-type glycoprotein, epitectin, from human urine: structures of the major oligosaccharide alditols. Glycoconj J 1998; 15: 37-49.

[19] Bader SA, Harris H. Regulation of epitectin production in a malignant cell line. J Cell Sci 1987; 87: 375-81.

[20] Callahan HJ, Byrne D, Fritz R, Mulholland SG. Urinary bladder glycoproteins of the rabbit: extraction, biochemical and immunological studies. Immunol Invest 1985; 14: 41-55.

[21] Taddei-Peters WC, Bhavanandan VP, Davidson EA. Purification and partial characterization of a malignancy-associated glycoprotein. Carbohydr Res 1988; 182: 135-47.

[22] Devaraj N, Devaraj H, Bhavanandan VP. Purification of mucin glycoproteins by density gradient centrifugation in cesium trifluoroacetate. Anal Biochem 1992; 206: 142-6.

[23] Erickson DR, Ordille S, Martin A, Bhavanandan VP. Urinary chondroitin sulfates, heparan sulfate and total sulfated glycosaminoglycans in interstitial cystitis. J Urol 1997; 157: 61-4.

[24] Krueger RC Jr, Schwartz NB. An improved method of sequential alcian blue and ammoniacal silver staining of chondroitin sulfate 
proteoglycan in polyacrylamide gels. Anal Biochem 1987; 167: 295-300.

[25] Fairbanks G, Steck TL, Wallach DF. Electrophoretic analysis of the major polypeptides of the human erythrocyte membrane. Biochemistry 1971; 10: 2606-17.

[26] Sachdev GP, Fox OF, Wen G, Schroeder T, Elkins RC, Carubelli $\mathrm{R}$. Isolation and characterization of glycoproteins from canine tracheal mucus. Biochim Biophys Acta 1978; 536: 184-96.

[27] Nesterenko MV, Tilley M, Upton SJ. A simple modification of Blum's silver stain method allows for 30 minute detection of proteins in polyacrylamide gels. J Biochem Biophys Methods 1994; 28: 239-42.

[28] Bramwell ME, Ghosh AK, Smith WD, Wiseman G, Spriggs AI, Harris $\mathrm{H}$. Ca2 and Ca3. New monoclonal antibodies evaluated as tumor markers in serous effusions. Cancer 1985; 56: 105-10.

[29] Bhavanandan VP, Ringler NJ, Gowda DC. Identification of the glycosidically bound sialic acid in mucin glycoproteins that reacts as "free sialic acid" in the Warren assay. Glycobiology 1998; 8: 1077-86.

[30] Cohen SA, Meys M, Tarvin TL. Pico-Tag advanced methods manual. In: A Manual of Advanced Techniques for Amino Acid Analysis, Millipore Corporation Publishing 1989; 2-57.

[31] Lee YC. High-performance anion-exchange chromatography for carbohydrate analysis. Anal Biochem 1990; 189: 151-62.

[32] Bhavanandan VP, Katlic AW. The interaction of wheat germ agglutinin with sialoglycoproteins. The role of sialic acid. J Biol Chem 1979; 254: 4000-8.
[33] Furukawa K, Minor JE, Hegarty JD, Bhavanandan VP. Interaction of sialoglycoproteins with wheat germ agglutinin-sepharose of varying ratio of lectin to Sepharose. Use for the purification of mucin glycoproteins from membrane extracts. J Biol Chem 1986; 261: 7755-61.

[34] Dische Z. A new specific color reaction of hexuronic acids. J Biol Chem 1947; 167: 189-98.

[35] Moon PG, Hwang HH, Boo YC, Kwon J, Cho JY, Baek MC. Identification of rat urinary glcyproteome captured by three lectins using gel and LC-based proteomics. Electrophoresis 2008; 29: 1-8.

[36] Grant AM, Neuberger A. The development of a radioimmunoassay for the measurement of urinary Tamm-Horsfall glycoprotein in the presence of sodium dodecyl sulphate. Clin Sci 1973; 44: 163-79.

[37] Muchmore AV, Decker JM. Uromodulin: a unique 85-kilodalton immunosuppressive glycoprotein isolated from urine of pregnant women. Science 1985; 229: 479-81.

[38] Devuyst O, Dahan K, Pirson Y. Tamm-Horsfall protein or uromodulin: new ideas about an old molecule. Nephrol Dial Transplant 2005; 20: 1290-4.

[39] Flynn FV, Lapsley M, Sansom PA, Cohen SL. Urinary excretion of beta 2-glycoprotein-1 (apolipoprotein $\mathrm{H}$ ) and other markers of tubular malfunction in "non-tubular" renal disease. J Clin Pathol 1992; 45: 561-7.

(C) Muthusamy et al.; Licensee Bentham Open

This is an open access article licensed under the terms of the Creative Commons Attribution Non-Commercial License (http://creativecommons.org/licenses/by-nc/3.0/) which permits unrestricted, non-commercial use, distribution and reproduction in any medium, provided the work is properly cited. 